
EDUCACIONAL EM TEMPOS DE RUPTURAS POLÍTICAS

Gladson Paulo Milhomens Fonseca

\title{
UM IMAGINÁRIO DE RESISTÊNCIAS: PROPOSTA PARA UMA PRÁXIS EDUCACIONAL EM TEMPOS DE RUPTURAS POLÍTICAS
}

\author{
UN IMAGINARIO DE RESISTENCIAS: PROPUESTA PARA \\ UNA PRAXIS EDUCATIVA EN TIEMPOS DE RUPTURAS POLÍTICAS
}

Gladson Paulo Milhomens Fonseca

\section{RESUMO}

A ideia desse artigo surgiu através de uma exposição do sociólogo brasileiro Jessé Souza e sua leitura atenta sob o complexo cenário atual pósimpeachment no Brasil, elencando os desafios da quebra do pacto com as elites após o regime militar e a transição democrática até a Constituinte de 1988. A partir de reflexões de autores como Michel Foucault e Florestan Fernandes, apresento uma proposta para desenvolvimento de um imaginário de resistências - com enfoque tanto histórico como sociológico.

Palavras-chave: Crise política. Ciências Sociais. Imaginário de resistência.

\section{RESUMEN}

Con el golpe jurídico-parlamentar contra el mandato presidencial de Dilma Rousseff no Brasil, é necesario desarrollar nuevas plataformas de lucha política no campo educacional y cultural. La medida que las democracias del siglo XXI crean sinales de solidez institucional acerca de un Estado de bienestary derechos civiles (laborales, previdencia, educacionales e salud) con la nueva ordene ultraliberale, el mondo cruza más una crisis del sistema 


\title{
UM IMAGINÁRIO DE RESISTÉNCIAS: PROPOSTA PARA UMA PRÁXIS EDUCACIONAL EM TEMPOS DE RUPTURAS POLÍTICAS
}

\author{
Gladson Paulo Milhomens Fonseca
}

capitalista. La perspectiva histórica de Eric Hobsbawm (2012), con los períodos que cambian para lo capitalismo de siglo $\mathrm{XX}$, en resumen, introducen mecanismos de reinvención de la orden exploratoria de su modo de producir, colocando lo neofascismo como ideología de exceción: lo camino para la crisis marcha pela derecha. Neso inicio de siglo XXI, los fantasmas del pasado resurgen na Europa dividida, protagonizando el Brexiten lo Reino Unido, así como a elección do polémico empresario Donald Trump a presidencia de los EE.UU - llegando a el poder por defender propuestas calcadas na violación a los Derechos Humanos. A el mismo tiempo que esos civismos intolerantes llegan a América Latina, el ciclo de gobiernos progresistas na región presenta sinales claros de desgaste: Macri na Argentina y lo parlamento vilipendioso de Temer en Brasil ponen lo Sur continental como área satélite derecha de los industriales del petróleo norte-americano, así como lo grande capital representado por Wall Street. No panorama externo euroasiático, Rússia y China sieguen pelo Oriente, Eurásia, Cáucaso. Los russos colocan lo Norte da Europa (Escandinávia) en sinal de alerta. Una imagen desoladora para las reconfiguraciones que se parecen a los fantasmas do pasado, revestidos con nuevos ingredientes y creando largo espacio na Internet (Google, Microsoft, Facebook, etc.), posibles de pulverizar saberes articulando nuevos mecanismos de información instantánea. Lo objetivo de esa comunicación es mover una propuesta de un imaginario de resistencias sobre el escenario actual, sobretodo como propuesta educacional, histórica e sociológica. Como ben habló lo sociólogo Boaventura Santos (1989) sobre el dualismo Estado/Sociedad civil: cargado de problemas y crisis constantes por su carácter exploratorio histórico haturale.

Palabras clave: Crisis política. Ciencias Sociales. Imaginario de resistências. 


\section{CONSIDERAÇÕES INICIAIS}

A proposta desse artigo visa discutir os problemas enfrentados por cientistas sociais brasileiros com o novo golpe, visando uma construção criativa e imaginária acerca da ruptura constitucional que estamos passando. Neste prelúdio, voltemos rapidamente ao dia 17 de abril de 2016. O que deveria ser uma votação parlamentar na Câmara dos Deputados em Brasília, traduz-se num patético circo de horrores televisionado. Durante a votação e as palavras de ordem dos deputados, tem-se a impressão de que a confusa e turbulenta passagem dos militares e civis para a Nova República brasileira (1988) está sob novo abalo sísmico. Aqui a História não fica incólume e, sobretudo no Brasil, onde mal acabara de existir - após 28 anos - a democracia é colocada como um entrave aos interesses das elites nacionais.

Por unanimidade, jurídica e midiática, os setores resistentes das antigas oligarquias nacionais resolvem disparar sua euforia escatológica: sim, a abertura do processo de impeachment contra a presidenta Dilma já estava devidamente pavimentado. A partir daquele momento, o Brasil mergulha em outro calvário antidemocrático, por assim dizer, consolidando novas forças conservadoras. Neste cenário contemporâneo, os poderes judiciário e legislativo resolvem institucionalizar toda e qualquer medida que se colocasse como baliza aos interesses da nova ruptura constitucional.

Certamente, não podemos esquecer que o Brasil adotou a narrativa de golpes - militares ou não - através da estrutura republicana desde 1889 (fundada com os mesmos anseios pelo Clube de Oficiais do Rio de Janeiro). Neste caso, torna-se uma regra tácita em nossa trajetória nacional. No artigo intitulado A luta popular pela Constituição (1985), publicado originalmente no jornal Folha de São Paulo, o sociólogo Florestan Fernandes nos adverte para esse caráter mudancista da chamada transição democrática: como foram feitos os acordos entre os agentes do Colégio Eleitoral de Tancredo Neves e a ala dos militares desfavoráveis à democracia? 


\title{
UM IMAGINÁRIO DE RESISTÉNCIAS: PROPOSTA PARA UMA PRÁXIS EDUCACIONAL EM TEMPOS DE RUPTURAS POLÍTICAS
}

\author{
Gladson Paulo Milhomens Fonseca
}

Jessé Souza, um atento sociólogo brasileiro, analisa em seu recente trabalho $A$ radiografia do golpe (2016) a arquitetura jurídica e midiática que tomou conta do país a partir das manifestações de junho de 2013. O que levou tantos brasileiros e brasileiras às ruas nos quatro cantos do país? Desde as Diretas Já (1984) não se via tantas pessoas ocupando as ruas. Por outro lado, a ausência de uma agenda político-partidária ou puramente contestatória no sentido mais radical do termo, parece confundir até os espectadores mais atentos. $O$ que aparentemente emergia como passeatas contra o aumento abusivo de tarifas de transporte público em várias cidades, rapidamente desconecta-se de um viés progressista. Como bem definiu Souza, a direita resolveu sair do armário. Surge rapidamente na cena das manifestações subsequentes, uma bandeira anticorrupção que passa a criminalizar o governo do Partido dos Trabalhadores (PT).

Neste cenário, devemos compreender que a matriz do Pensamento Social Clássico é um instrumento viável para que o sociólogo numa dada situação de emergência política se posicione sobre a atual ruptura constitucional que estamos vivendo. No cenário pós-impeachment, como possibilitar às Ciências Sociais sua função educacional, epistemológica e reflexiva, que se (re)invente? Parte dos objetos de cena que são colocados agora nesta encenação rompem completamente com o pacto da Carta de 1988. Como já podemos observar, a publicação da Medida Provisória ํo 746, coloca por terra qualquer possibilidade de diálogo entre o saber sociológico já instituído no Brasil e seu futuro como ciência.

\section{UM IMAGINÁRIO DE RESISTÊNCIAS}

Até onde as democracias são interessantes para o capitalismo? Micah White, ativista pelos Direitos Humanos (idealizador do movimento Occupy Wall Street) traz uma reflexão importante: a democracia está em crise porque o dinheiro controla os governos. Talvez aí, resida o teto de vidro da democracia. Às vésperas deste evento, por exemplo, o país assiste à aprovação na Câmara 


\title{
UM IMAGINÁRIO DE RESISTÊNCIAS: PROPOSTA PARA UMA PRÁXIS
} EDUCACIONAL EM TEMPOS DE RUPTURAS POLÍTICAS

\author{
Gladson Paulo Milhomens Fonseca
}

(já seguindo para o Senado Federal até meados de dezembro de 2016) a Proposta de Emenda Constitucional 241/55, com o objetivo de reduzir o papel do estado na economia. O período proposto é alarmante: vinte anos com redução drástica para as áreas de saúde e educação. A chamada gestão Temer não dialoga com a sociedade civil. Ou parece demonstrar isso.

A lógica da função pública sobre o estado em relação ao cidadão é consequência dos ciclos de transformação capitalista desde meados do século XIX. Paradoxalmente, cada vez mais o estado assume uma função privatista (sobretudo em setores estratégicos e que dizem respeito à soberania de um povo). Vale dizer que não se trata de um panorama apenas endógeno, mas sobretudo exógeno. $O$ enfraquecimento de uma ordem democrática não é fruto apenas de interesses vinculados às elites tupiniquins, mas envolve uma gama de outros interesses que envolvem a construção dos desejos maiores de uma expansão/exploração do mercado externo.

Merecidamente, sociólogos e historiadores agora formam um importante dueto para as Ciências Sociais e seu ofício ad referendum para construir novas práticas de atuação no Ensino Médio e Superior. Como metodologia resistente, proponho a utilização de imagens como um método instrumental de consolidar novas imagens. Neste mesmo panorama das imagens, reside o papel de um certo tipo de fundação imaginativa que merece atenção: ela é o esforço de várias etapas e informações necessárias à formulação intelectual do(a) sujeito(a) e pode ser estimulada tanto dentro como fora da universidade. Assim, podemos explorar:

1) Aulas públicas.

2) As novas mídias e métodos contra-hegemônicos.

3) A elaboração teórica e prática de novas redes de produção de conhecimento e informação (internet, rádio, informativos, etc.) envolvendo público não acadêmico e acadêmico.

Ao partir para uma luta cotidiana - seja como pesquisador ou professor - o pesquisador de Ciências Sociais precisa estar preparado para requerer a si 


\title{
UM IMAGINÁRIO DE RESISTÊNCIAS: PROPOSTA PARA UMA PRÁXIS EDUCACIONAL EM TEMPOS DE RUPTURAS POLÍTICAS
}

\author{
Gladson Paulo Milhomens Fonseca
}

não apenas um olhar interdisciplinar, mas uma produção, sobretudo, transdisciplinar. A consolidação imaginária da resistência não pode ficar determinada à torre dos cristais (muros da academia). $O$ isolamento acadêmico à esta altura precisará tomar partido de algo, mesmo que cometa certo maniqueísmo. Gostaria, sobretudo, de agradecer à socióloga Tania Magno (Universidade Federal de Sergipe) e seus comentários sobre minha apresentação com imagens instrumentalizadas (que contou com a participação de outros docentes e discentes no evento Ensino de Ciências Sociais em tempos de exceção) que possuem um tom político passional. Certamente, contrapor imagens é a melhor didática em aulas públicas.

No exato momento em que concluo esse texto, Donald Trump é eleito presidente dos E.U.A. O mais importante nesse momento - além de uma profunda análise sociológica e histórica - é reconhecer que o ultraliberalismo ganha cor e forma nas novas imagens que permeabilizam o American dream (Sonho americano). A sua ameaça ou, seu suposto declínio, provocou uma insurreição no establishment nos redutos eleitorais do Partido Democrata, colocando o magnata do Meio-Oeste americano do Norte como o 45은 presidente daquele país. $\mathrm{O}$ que resistirá a mudanças tão abrutas do sistema capitalista? Certamente é uma reviravolta no modelo econômico global, mas a imagem imposta socialmente neste momento é de uma suposta apartidarização (leia-se, também, apolitização) das velhas formas de "fazer política". Dessa forma, nosso suposto modelo ocidental e civilizacional é um projeto em crise e as sociedades deste início de século terão um grande desafio.

\section{REFERÊNCIAS}

CONSTITUIÇÃO da República Federativa do Brasil: texto constitucional promulgado em 5 de outubro de 1988, com as alterações adotadas pelas Emendas Constitucionais no 1/92 a 38/2002 e pelas Emendas Constitucionais 
o 1/92 a 38/2002 e pelas Emendas Constitucionais de Revisão números 1 a 6/94. - Brasília: Senado Federal, Subsecretaria de Edições Técnicas, 2002.

FERNANDES, Florestan. Que tipo de república?. (Coord.) Maria Arminha do Nascimento. São Paulo: Globo, 2002.

FOUCAULT, Michel. Os intelectuais e o poder - conversa entre Michel Foucault e Giles Deleuze. In: Microfísica do poder. Rio de Janeiro: Graal, 1979.

SOUZA, Jessé. A radiografia do golpe. Disponível em:

https:/lerlivros.online/livro/A+radiografia+do+Golpe/ Acesso em 05/11/2016. 